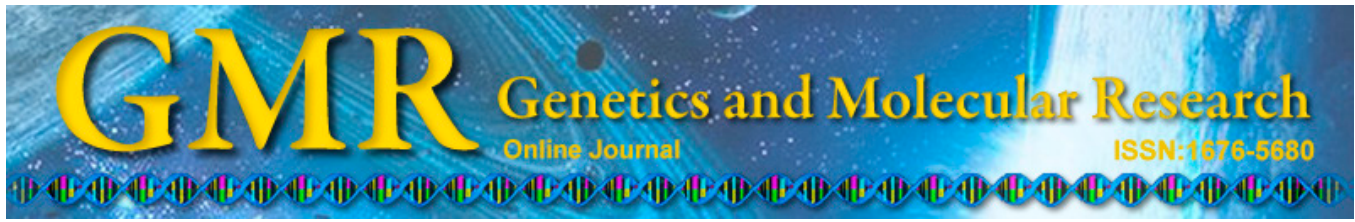

\title{
Expression and clinical significance of CD4+ CD45+ peripheral blood $T$ cells in patients with ulcerative colitis
}

\author{
L.Y. Guo, Y.R. Li and X.P. Jin \\ The First Affiliated Hospital of Liaoning Medical University, \\ Jinzhou, Liaoning, China \\ Corresponding author: X.P. Jin \\ E-mail: jianxupeng_1@163.com
}

Genet. Mol. Res. 14 (3): 10338-10343 (2015)

Received February 12, 2015

Accepted May 25, 2015

Published August 28, 2015

DOI http://dx.doi.org/10.4238/2015.August.28.20

\begin{abstract}
The objectives of this study were to explore the expression of peripheral blood $\mathrm{CD} 4+\mathrm{CD} 45+\mathrm{T}$ cells in patients with ulcerative colitis (UC) and determine its clinical value. We selected 80 patients with UC from the First Affiliated Hospital of Liaoning Medical University from March 2012 to December 2013. Of these, 27 had mildly active, 28 moderately active, and 25 severely active UC. We also recruited 80 subjects to constitute the healthy control group. The percentages of $\mathrm{CD} 4+\mathrm{CD} 45+$ molecules on the peripheral blood $\mathrm{T}$ cell surfaces of patients were detected using flow cytometry and were compared between patients to determine the severity of illness. The percentage of peripheral blood CD4+CD45+T cells in the UC group was $52.93 \pm 3.64 \%$ and in the controls it was $41.34 \pm 2.94 \%$; the UC group percentages were significantly higher $(t=-22.159, \mathrm{P}<$ $0.05)$. The average percentages in patients with mild, moderate, and severe activity were $50.99 \pm 1.45,52.66 \pm 1.41$, and $55.18 \pm 2.18 \%$, respectively; the moderate activity percentage was higher than that of mild activity, and the severely active stage percentage was overall the highest. Comparison between groups showed a statistically significant
\end{abstract}


difference, $\mathrm{F}=39.850,(\mathrm{P}<0.05)$. The expression levels of peripheral blood CD4+CD45+ T cells in the UC group were higher than those in the control group. Overall, our results showed that with the aggravation of disease the peripheral blood CD4+CD45+ T cell percentages were significantly increased, which might be useful as a marker for clinical diagnosis.

Key words: Ulcerative colitis; CD4+CD45+ regulatory T cells; Flow cytometry; Immune regulation.

\section{INTRODUCTION}

Ulcerative colitis (UC) is a common intestinal inflammatory disease. The lesions of UC involve the mucosa and submucosal tissue, and mostly locate in distal rectum and colon but can expand to the proximal regions, and even throughout the whole colon. UC clinically manifests as a chronic history, with symptoms including diarrhea or constipation, stool with blood, pus, and tenesmus, the presence of absence of abdominal pain, and repeated attacks. The etiology and pathogenesis of UC are still not clear (Kamada et al., 2008). UC might be the result of concurrent effects of the environment, inheritance, infection, immunity, spirit, intestinal flora, and allergies, although immune dysfunction is thought to constitute the key factor of UC (Lord et al., 2012). It has recently been discovered that the presence of CD4+CD45+ on regulatory T cells (Tregs) plays an important role in patients with UC (Furihata et al., 2006). In this study, we examined 80 patients with UC, and determined that the percentage of peripheral blood $\mathrm{T}$ cell expression of $\mathrm{CD} 4+\mathrm{CD} 45+$ was in the range of $52.93 \pm 3.64 \%$, providing evidence potentially relevant to clinical diagnosis. By comparing the expression of CD4+CD45+ in mild, moderate, and severe $\mathrm{UC}$, we determined that as the disease becomes aggravated, the expression of these markers increased, which might be useful in judging the severity of the disease.

\section{MATERIAL AND METHODS}

\section{Subjects}

We randomly selected 80 patients with active UC, including 44 men and 36 women aged between 32 to 66 years ( $49 \pm 3$ years) hospitalized for treatment at the First Affiliated Hospital of Liaoning Medical University Digestive Department between March 2012 and December 2013. All diagnoses referred to the suggested diagnosis and treatment consensus criteria for inflammatory bowel disease in China in 2012, which were established by the Chinese Medical Association Gastroenterology Chapter Inflammatory Enterology Group in Guangzhou (Chinese Medical Association of Gastroenterology Inflammatory Bowel Disease Study Group, 2013). According to de Souza et al. (2012), we divided the 80 patients into 27 in a mildly active phase, 28 in a moderately active phase, and 25 in a severely active phase. We also recruited a healthy control group including 80 volunteers, 41 men and 39 women aged 27 to 61 years ( $47 \pm 4$ years), without diarrhea or any history of autoimmune or familial inherited diseases. There were significant differences in age and gender ratio between the patient and control groups. 


\section{Instruments and reagents}

Human Ficoll lymphocyte separating reagent was obtained from Shanghai 3bio Biotechnology Co., Ltd. (Shanghai, China). Fluorescein isothiocyanate (FITC) labeled antiCD4 and phycoerythrin (PE) labeled anti-CD45 antibodies were obtained from Shanghai YU PING Biotechnology Co. Ltd. (Shanghai, China). RPMI1640 was obtained from GibcoBRL (Gaithersburg, MD, USA). The flow cytometry FACScanto II instrument was obtained from Becton-Dickinson (Bedford, MA, USA).

\section{Methods}

Morning venous blood $(5 \mathrm{~mL})$ was drawn from the veins of patient and control groups, and heparin was added as an anticoagulant. In the 6th $\mathrm{h}$ after blood collection, each sample was centrifuged at $1500 \mathrm{rpm}$ by Ficoll density gradient centrifugation to separate out the peripheral blood mononuclear cells, which were then filtered with a 200-mesh filter. The cell suspension was washed with RPMI1640-2 twice and the concentration was adjusted to $1 \times 10^{5}$ cells $/ \mathrm{mL}$. The FITC-labeled anti-CD4 and PE-labeled anti-CD45 antibodies were added, and the suspension was incubated at room temperature for $30 \mathrm{~min}$. Then, the cells were washed twice with phosphate buffered saline, centrifuged at $2000 \mathrm{rpm}$ for $5 \mathrm{~min}$, and the supernatant was discarded. Labeled cells were detected with a flow cytometry FACScanto II; an isotype was used as the negative control to eliminate the autofluorescence background and a blank was used to eliminate non-specific fluorescence. The cells were gated to separate out the lymphocytes under the given conditions. We obtained the percentage of CD4+CD45+ cells according to the analysis of monoclonal antibodies combining with the amount and percentage of positive cells settled.

\section{Statistical analysis}

Means and SDs $( \pm)$ were used for descriptive purposes. The measurement data are reported as means \pm SDs. Using SPSS17.0 (SPSS, Chicago, IL, USA), data were analyzed by the Student $t$-test, and the comparison between groups was analyzed by analysis of variance. A value of $\mathrm{P}<0.05$ was considered to be statistically significant.

\section{RESULTS}

The observed expression of peripheral blood CD4+CD45+ T cells in the UC group $(52.93 \pm 3.64 \%)$ was significantly higher than that in the control group $(41.34 \pm 2.94 \%)(t=$ $-22.159, \mathrm{P}<0.05)$, which might provide evidence use of this measure for clinical diagnosis (Figure 1).

The expression of peripheral blood CD4+CD45+ T cells in patients with mildly active UC was $50.99 \pm 1.45 \%$, while that in moderately active UC was $52.66 \pm 1.41 \%$, significantly higher than values in normal individuals; the percentage in severe UC was $55.18 \pm 2.18 \%$, significantly higher than that in moderately active UC $(\mathrm{F}=39.850, \mathrm{P}<0.05)$. With the aggravation of $\mathrm{UC}$, the expression of peripheral blood CD4+CD45+ T cells became obviously increased; this finding might be of assistance in judging the severity of the disease (Figure 2). 


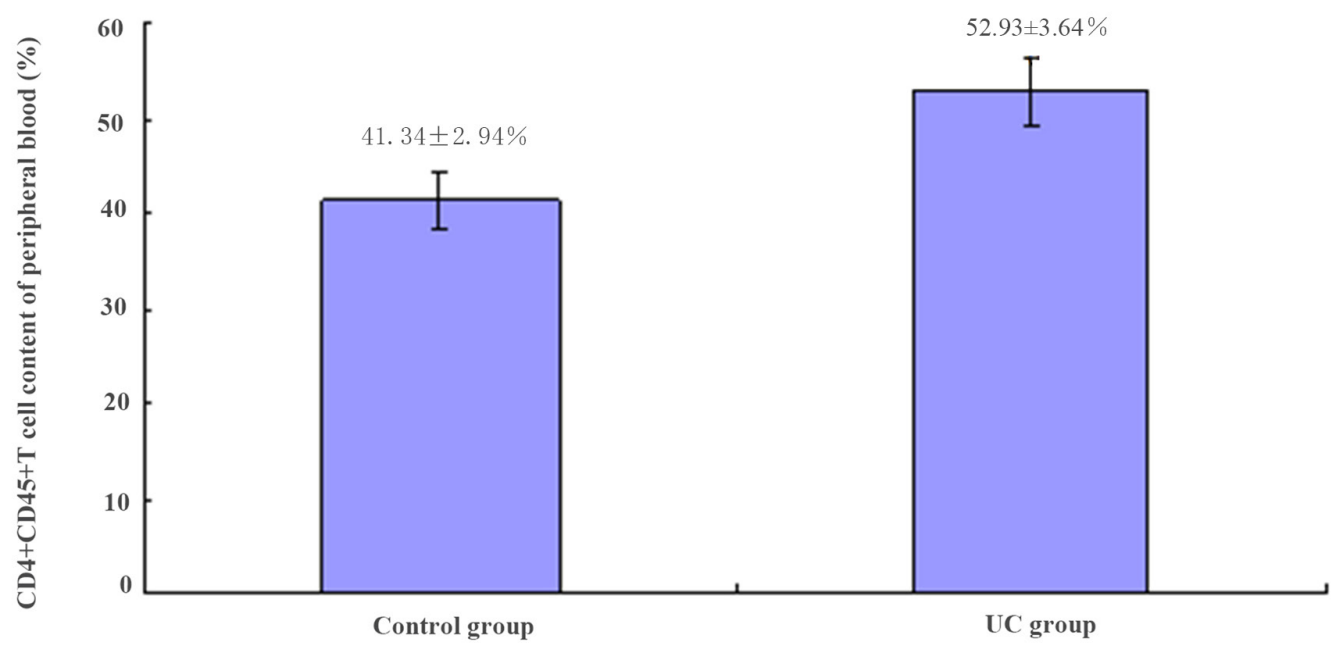

Figure 1. Comparison of peripheral blood CD4+CD45+ T cell content between control and ulcerative colitis (UC) groups. The UC group was compared to the healthy controls, $\mathrm{P}<0.05$.

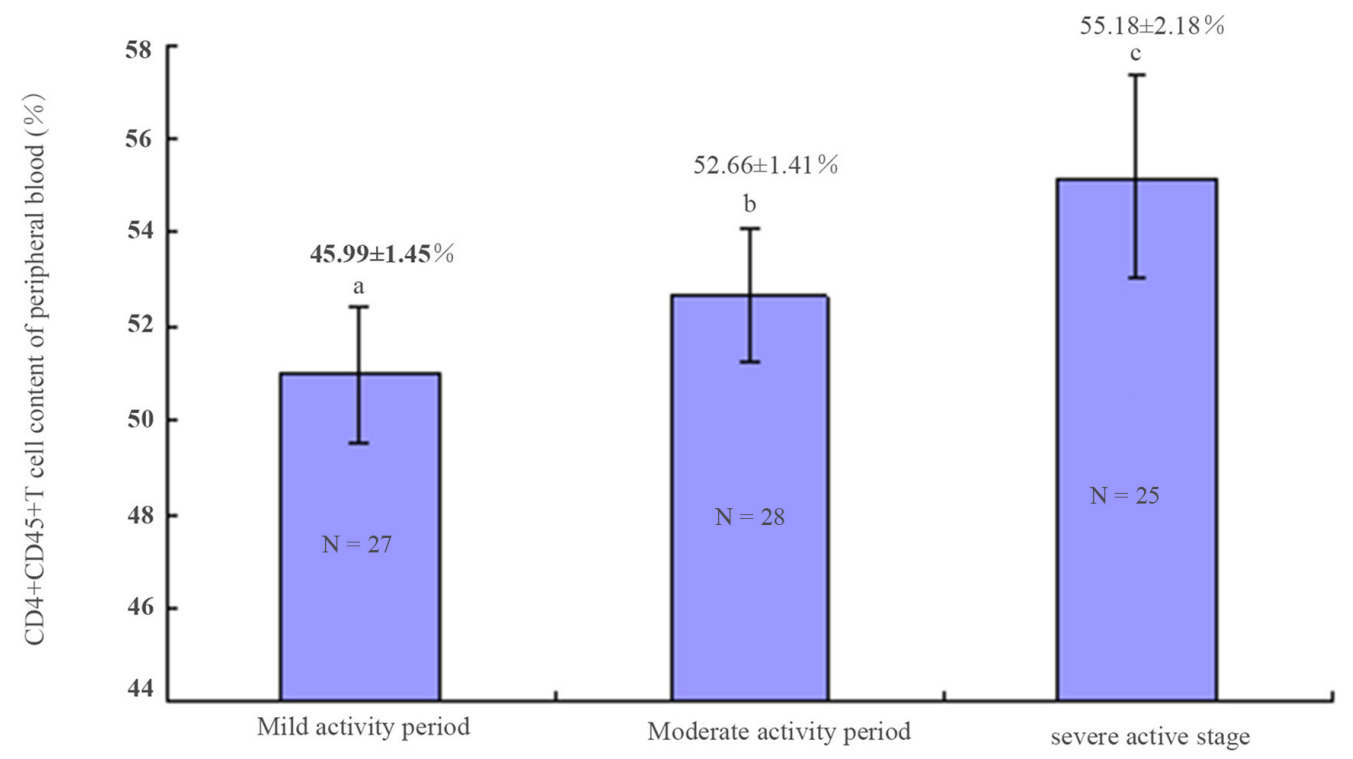

Figure 2. Comparison of peripheral blood $\mathrm{CD} 4+\mathrm{CD} 45+\mathrm{T}$ cell content between different disease activity periods (severities). Comparison of disease activity periods, $\mathrm{Pa}<0.05, \mathrm{~Pb}<0.05, \mathrm{Pc}<0.01$.

\section{DISCUSSION}

The commonplace disease UC is an inflammatory disease of the colon and rectum. Scholars worldwide have found that an abnormal reaction of the intestinal mucous membrane 
immune system was the most important factor contributing to the imbalance of the intestinal mucous membrane immune response and leading to the breakdown of immune defense (Dahlén et al., 2013). Normally, when antigens of bacterial or other origin induce and activate the immune cells in the intestinal mucosa, the immune cells transfer to the intestinal epithelial cell layer and the lamina propria after differentiation and maturation, which hosts the immune response and defends the body from the intrusion of harmful substances (Liu et al., 2008; Mao and Wang, 2010). In UC, the lymphocytes in colon mucosa become abnormally activated in response to antigens which should have induced adaptive immunity; many factors contribute to this phenomenon, of which $\mathrm{T}$ cells have been shown to comprise the most important immunocompetent cells (Radulovic et al., 2013).

$\mathrm{CD} 4+\mathrm{CD} 45+\mathrm{T}$ cells are regulatory $\mathrm{T}$ cells. $\mathrm{CD} 4+$ provides an auxiliary function in antigen-recognition receptors, while CD45+ is expressed in many kind of cells including blood and tumor cells and primarily in endothelial cells, and affects the differentiation of hematopoietic stem cells and the generation and metastasis of tumor cells (Liao et al., 2012). CD4+CD45+ T cells mainly assist the B cells. An increase in their number could lead to activation of $\mathrm{B}$ cells and the induction of reactions mediated by CD8, which could lead to dysfunctional immune response and pathogenicity (Lee et al., 2011;Yamamoto-Furusho et al., 2011; Katsurada et al., 2012; Dias et al., 2014).

When the mucosal immune system in the intestine is invaded by harmful substances in patients with UC, the immunologic balance can be disrupted, and the lymphoid tissue related to the line of first defense of intestinal mucosa can become activated, triggering an immune response (Galitovskiy et al., 2011). T cells play and important role in immune response and regulate the immunologic balance (Chao et al., 2011). CD4+CD45+, as the surface molecules on $\mathrm{T}$ cells, when activated by antigen stimulation, cause the active expression and secretion of large numbers of cytokines including IL-4, IL-5, IL-6, IL-10, and IL-13, accelerating immunoregulation (Katsurada et al., 2012; Bamias et al., 2013). When the antigenic effect is larger than is necessary for the immunoregulation function, it is likely to result in a disease state (Pilarczyk-Zurek et al., 2013).

By flow cytometry, we detected the percentage of $\mathrm{T}$ cell $\mathrm{CD} 4+\mathrm{CD} 45+$ surface molecules in peripheral blood of 80 patients with UC $(52.93 \pm 3.64 \%)$, which was significantly higher than that observed in the 80 volunteers $(41.34 \pm 2.94 \%)$. Thus, these results showed that the peripheral blood $\mathrm{T}$ cell $\mathrm{CD} 4+\mathrm{CD} 45+$ surface molecules were expressed at high levels in UC, which could lead to immune unbalance and result in disease; this finding provides evidence which could be used for clinical diagnosis. The expression of peripheral blood CD4+CD45+ T cells in patients with UC in a mildly active phase was $50.99 \pm 1.45 \%$, while that in moderately active UC was $52.66 \pm 1.41 \%$, and in severe UC was $55.18 \pm 2.18 \%$. As the aggravation of UC became enhanced, the expression level of CD4+CD45+ T cells markedly increased, which likely aggravated the immune unbalance and the severity of disease. Thus, measurement of the expression of peripheral blood T cell CD4+CD45+ surface molecules in patients with UC might be of use in helping to judge the severity of UC.

In conclusion, this study demonstrated that the expression of peripheral blood $\mathrm{T}$ cell $\mathrm{CD} 4+\mathrm{CD} 45+$ surface molecules in patients with UC was higher than that in healthy individuals. $\mathrm{CD} 4+\mathrm{CD} 45+\mathrm{T}$ cells play a role in the process of immunoregulation, and their numbers increase obviously along with the severity of disease aggravation; this finding might have significance for guiding clinical diagnosis and the judgment of disease severity. 


\section{Conflicts of interest}

The authors declare no conflict of interest.

\section{ACKNOWLEDGMENTS}

Research funded by the Liaoning Medical University Principal Fund (\#ZZJJ20130207) and the Natural Science Foundation of Liaoning Province (\#2013022005).

\section{REFERENCES}

Bamias G, Jia LG and Cominelli F (2013). The tumor necrosis factor-like cytokine 1A/death receptor 3 cytokine system in intestinal inflammation. Curr. Opin. Gastroenterol. 29: 597-602.

Chao K, Zhong BH, Zhang SH, Gong XR, et al. (2011). Imbalance of CD4(+) T cell subgroups in ulcerative colitis. Zhonghua Yi Xue Za Zhi 91: 1605-1608.

Dahlén R, Strid H, Lundgren A, Isaksson S, et al. (2013). Infliximab inhibits activation and effector functions of peripheral blood T cells in vitro from patients with clinically active ulcerative colitis. Scand. J. Immunol. 78: 275-284.

de Souza HS, West GA, Rebert N, de la Motte C, et al. (2012). Increased levels of surviving, via association with heat shock protein 90, in mucosal T cells from patients with Crohn's disease. Gastroenterology 143: 1017-1026.

Dias AM, Dourado J, Lago P, Cabral J, et al. (2014). Dysregulation of T cell receptor N-glycosylation:a molecular mechanism involved in ulcerative colitis. Hum. Mol. Genet. 23: 2416-2427.

Furihata M, Sawada T, Okada T, Ishizuka M, et al. (2006). Total colectomy improves altered distribution of regulatory T cells in patients with ulcerative colitis. World J. Surg. 30: 590-597.

Galitovskiy V, Qian J, Chernyavsky AI, Marchenko S, et al. (2011). Cytokine-induced alterations of $\alpha 7$ nicotinic receptor in colonic CD4 Tcells mediate dichotomous response to nicotine in murine models of Th1/Th17- versus Th2mediated colitis. J. Immunol. 187: 2677-2687.

Kamada N, Hisamatsu T, Okamoto S, Chinen H, et al. (2008). Unique CD14+intestinal macrophages contribute to the pathogenesis of Crohn disease via IL-23/IFN- $\gamma$ axis. J. Clin. Invest. 118: 2269-2280.

Katsurada T, Kobayashi W, Tomaru U, Baba T, et al. (2012). Decrease of peripheral andintestinal NKG2A-positive T cells in patients with ulcerative colitis. PLoS One 7: e44113.

Lee JC, Lyons PA, McKinney EF, Sowerby JM, et al. (2011). Gene expression profiling of CD8+ T cells predicts prognosis in patients with Crohn disease and ulcerative colitis. J. Clin. Invest. 121: 4170-4179.

Liao CM, Zimmer MI, Shanmuganad S, Yu HT, et al. (2012). Dysregulation of CD1d-restricted type II natural killer T cells leads to spontaneous development of colitis in mice. Gastroenterology 142: 326-334.

Liu L, Wang ZP, Xu CT, Pan BR, et al. (2008). Effects of rheum tanguticum polysaccharide on TNBS-induced colitis and CD4+Tcells in rat. World J. Gastroenterol. 9: 2284-2288.

Lord JD, Valliant-Sunders K, Hahn H, Thrilby RC, et al. (2012). Paradoxically increased FOXP3+ T Cells in IBD do not preferentially express the isoform of FOXP3 lacking exon 2. Dig. Dis. Sci. 57: 2846-2855

Mao JW and Wang YD (2010). Advances in understanding the pathogenesis of mucosal barrier dysfunction in inflammatory bowel disease. Shijie Huaren Xiaohua Zazhi 18: 695-698.

Pilarczyk-Zurek M, Chmielarczyk A, Gosiewski T, Tomusiak A, et al. (2013). Possible role of Escherichia coli in propagation and perpetuation of chronic inflammation in ulcerative colitis. BMC Gastroenterol. 13: 61.

Radulovic K, Rossini V, Manta C, Holzmann K, et al. (2013). The early activation marker CD69 regulates the expression of chemokines and CD4 T cell accumulation in intestine. PLoS One 8: e65413.

Yamamoto-Furusho JK, Álvarez-León E, Fragoso JM, Gozalishvilli A, et al. (2011). Protective role of interieukin-19 gene polymorphisms in patients with ulcerative colitis. Hum. Immunol. 72: 1029-1032. 